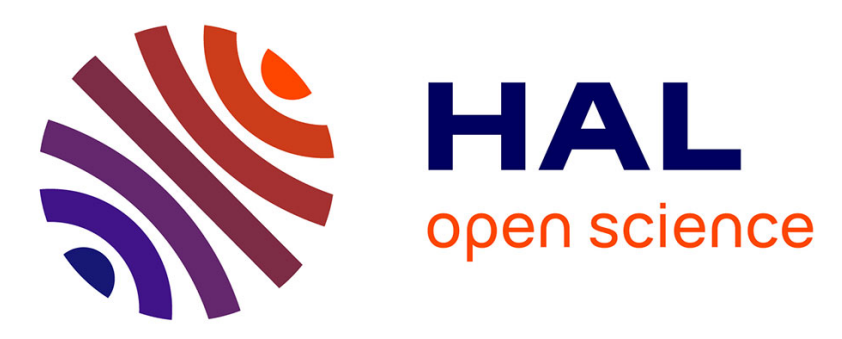

\title{
Geotechnical data standardization and management to support BIM for Underground Infrastructures and Tunnels
}

Mickaël Beaufils, Sylvain Grellet, Bastien Le Hello, Julien Lorentz, Maxime Beaudouin, Juan Castro-Moreno

\section{To cite this version:}

Mickaël Beaufils, Sylvain Grellet, Bastien Le Hello, Julien Lorentz, Maxime Beaudouin, et al.. Geotechnical data standardization and management to support BIM for Underground Infrastructures and Tunnels. WTC - World Tunnel Congress 2019, May 2019, Naples, Italy. hal-02056440

\section{HAL Id: hal-02056440 https: / hal-brgm.archives-ouvertes.fr/hal-02056440}

Submitted on 4 Mar 2019

HAL is a multi-disciplinary open access archive for the deposit and dissemination of scientific research documents, whether they are published or not. The documents may come from teaching and research institutions in France or abroad, or from public or private research centers.
L'archive ouverte pluridisciplinaire HAL, est destinée au dépôt et à la diffusion de documents scientifiques de niveau recherche, publiés ou non, émanant des établissements d'enseignement et de recherche français ou étrangers, des laboratoires publics ou privés. 


\title{
Geotechnical data standardization and management to support BIM for Underground Infrastructures and Tunnels
}

\author{
M. Beaufils \& S. Grellet \\ BRGM (French Geological Survey), Orléans, France
}

B. Le Hello
EGIS SE, Seyssins, France

J. Lorentz

Geolithe Innov, Crolles, France

\author{
M. Beaudouin \\ SYSTRA, Paris, France
}

\section{J. Castro Moreno}

SETEC als, Lyon, France

\begin{abstract}
:
In France, the MINnD project aims at extending Building Information Modeling (BIM) capacities for its application to infrastructures such as roads, bridges and railways. The MINnD Use Case 8 (UC8) is about Underground Infrastructures, and deals with both the description of the tunnel, its equipment parts and environment, with a main focus on pre-feasibility study to the construction phase.

This paper deals with the description of the environment part. It identifies exchange requirements in geotechnical engineering and introduce solutions for data organization and provision. This encompasses the standardization of data such as observations and measurements; geological, hydrogeological and geotechnical models; impact on anthropic and natural environment; structure sizing and proposition of construction methods and risk assessment.

In that context, propositions of reuse and extension of existing standards for geoscience data, such as GeoSciML and GroundWaterML2 from the Open Geospatial Consortium (OGC) are developed and discussed.
\end{abstract}

\section{INTRODUCTION}

Several definitions are often associated to the BIM acronym. While there is a consensus on saying that BI stands for Building Information, the $\mathrm{M}$ is often associated to multiple translations, the most popular being Model, Modeling or Management (Eastman, 2011). In brief, one can say that those three expressions respectively deal with the capacity of positioning accurately objects in space, explaining the methodology for getting it, and managing all those data during the building or infrastructure life cycle.

In the French MINnD project ${ }^{1}$, that aims at extending BIM capacities to cover infrastructure description, an initiative was launched to deal with Underground Infrastructure, also denominated as Use Case 8 or UC8. The perimeter includes the description and organization of data associated to the design of the construction with its equipment (covered by the GC subgroup), but also addresses the topic of environmental modeling (covered by the GT subgroup).

Geotechnics or geoengineering studies aim at collecting and combining information from the subsurface to characterize its consistence and propose solutions to enable the integration of a building or an infrastructure. This means that the data used and produced for geoengineering have a strong impact on the infrastructure design and shall be considered in BIM, as the data related to the construction or their equipment themselves.

\footnotetext{
${ }^{1}$ Official website: $\underline{\text { www.minnd.fr/en }}$
} 
Standardization in BIM is commonly associated to the development of the Industry Foundation Classes (IFC). Then actions on IFC Bridge for example focused on extending existing IFC or introducing new ones to be able to properly describe a bridge and its components. Following that approach, several initiatives proposed to extend IFC with geological or geotechnical concepts (China Railway BIM Alliance, 2015), (An, 2017). Such approach would offer some advantages; the most obvious is that it should facilitate compatibility with other IFCs. Yet, alternative solutions worth being considered too and a specific attention should be paid on two critical points:

First, environmental modeling follows different rules than Building Information Modeling. While BIM aims at defining the system to build and the actions to do to have it, geomodelling is about exposing what has been observed and possible interpretation that can be built from those observations. In that context, geomodeling is always associated to uncertainties. Then, to cope with them, the project coordinator relies on a risk driven management approach, focusing on the risk of delay and extra cost that each possible misinterpretation could lead to. In other words, this means that geotechnical activities do not (only) consist in the provision of a 3D map that describes the expected position, shape and properties of subsurface components, but aim at proposing infrastructure sizing and construction methods to build a sustainable infrastructure in acceptable risk conditions.

Second point is that several formats, communities and activities already exist for geoscience data standardization. Several organizations that produce environmental data even have to provide their data through specific standards according to legal rules (e.g. INSPIRE Directive in Europe). A sustainable and long-term proposition for coupling geoscience data with BIM shall integrate such dynamics and constraints, in order to avoid data duplication, limit data conversion, facilitate model updates and data maintenance in general.

Considering that context, the MINnD UC8-GT group first focused on eliciting the geotechnical activities, determining how the "geotechnical knowledge" is built and which data are used and produced to do so. Then the second activity was to study the existing standards, communities and activities around that topic. That study leads to propositions to organize geotechnical data in order to support BIM for Underground Infrastructure, with a focus on the design part of the project: this is basically the summary of that paper.

\section{GEOTECHNICAL ENGINEERING}

\subsection{General definition}

Geotechnical engineering is a specific part of civil engineering required to define and assess soils behavior during and after infrastructure construction. Studies are made following a detailed process from project beginning to ending in order to limit the risks associated to soils behaviors.

The geotechnical activities cover several fields of expertise as geology, geomechanics and hydrogeology and is completed by geotechnical investigations (borehole, in situ test, laboratory test). One of its main purposes is to define primary geological or hydrogeological risk of one project and propose adapted solution, requiring characterizing mechanical properties of soils and soil / structure interaction. Then, the geotechnical studies process follows classical design workflow of one infrastructure passing from prefeasibility and feasibility studies to detailed design studies, in framework of standard or specific guidelines.

\subsubsection{In France}

Several standards have been defined to ensure the quality and efficiency of French geoengineering. The French Coordination of Commissions in Geotechnical Standardization presented in (BNTRA, 2014) an overview of the applicable standards in France for the geotechnical engineering activity.

NF P 94500 is the French standard which specifies the geotechnical studies to be done, their nature and objective, and their workflow. Geotechnical studies workflow is organized around five main missions:

-G1 is the prefeasibility study. It aims at getting an overview of the main geological, hydrological and geotechnical risk associated to the site of the project, 
- G2 is the conception phase. It is separated into two main parts: the first is the identification and comparison of possible solutions for the project, the second is the development of the retained solution including costs and methodology. It ends with the preparation of tender documents to identify a constructor,

-G3 and G4 are made during the construction phase. G3 is specific to French methodology and corresponds to the geotechnical design of the company in charge of construction. G4 is the construction follow up.

-G5 is an expertise study that can be made on an existing structure.

Then NF P 94500 is not focused on Underground Infrastructure or tunnel construction, thus can be used for any kind of infrastructure or building construction.

Yet, for tunneling construction, the French Tunneling and Underground Space Association (AFTES), proposes several guidelines in order to specialize the objective of geotechnical mission described in NF P 94500 for tunneling project. MINnD UC8-GT group focused on the AFTES workflow and aims at describing information and data transmission from prefeasibility step to tendering step of a tunnel construction project, thus G1 and G2.

\subsubsection{In the other countries}

ISO/TC182 addresses the topic of geotechnics, yet with a focus on the description of the investigations and testing. It does not deal with the description of the general geotechnical activity processes. In that domain, international standards, especially British construction procedure differs from French standard on the fact that the company in charge of the construction do not have to perform additional geotechnical design during construction even if it is strongly advised.

Eurocode 7 is the European standard dealing with geotechnical design. It aims at describing how to design geotechnical structure and is split in two main documents (part 1 which is general rules and part 2 which is ground investigation and testing). In its two parts, but especially in part 2 , the geotechnical studies procedure is described from preliminary studies to project design. It is fully consistent with G1 and G2 phases of NF P 94500.

Then, considering the perimeter and focus of MINnD UC8 GT on the G1 and G2 phases, equivalence can be assumed for other countries as geotechnical studies and specifically design studies required for tender are similar (same objectives) inside and outside of France.

\subsection{Main topics in geotechnical works and perimeters}

\subsubsection{Decomposition of the geotechnical engineering activities}

Based on the NF P 94500 standards, nine topics have been identified as the main subdivisions of a geotechnical engineering project all over its life.

\section{GEOL, HYDRO, GTCH AVOI, ENVI, RISK}

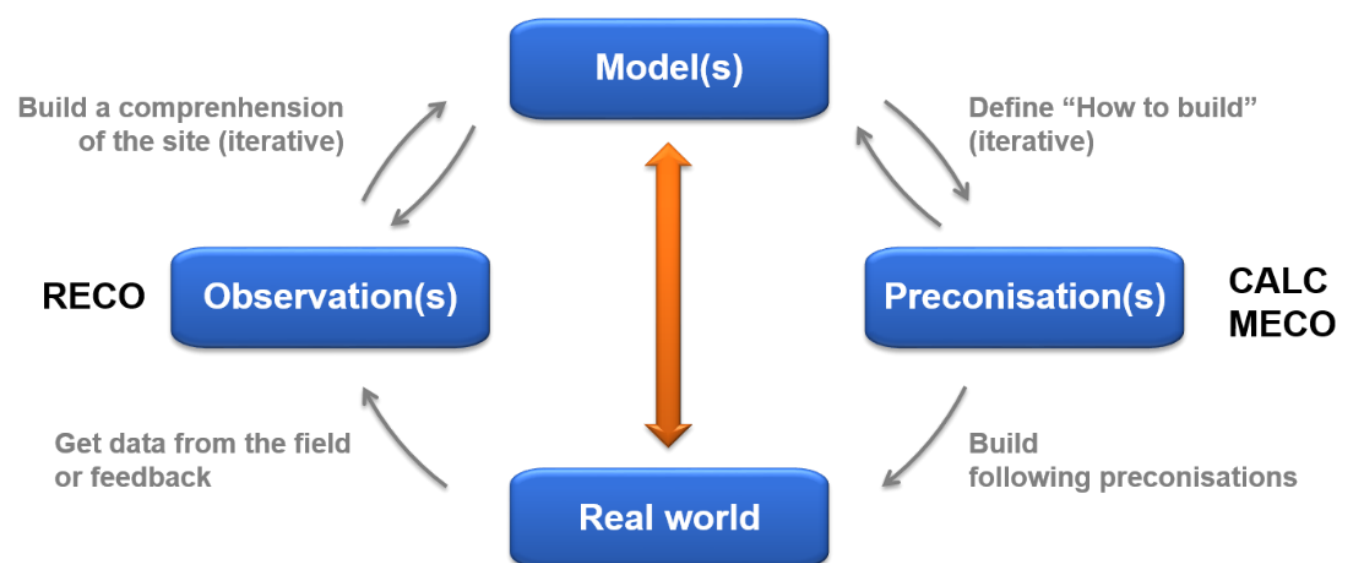

Figure 1: The main geotechnical activities 
The figure opposite (Figure 1) propose an abstract representation of the geotechnical activities and perimeter.

-RECO covers the data collection phase. It deals with the definition and execution of site investigations, measurements and laboratory tests,

-GEOL, HYDR and GTCH respectively deal with the modeling of the geological context, the hydrogeological context and the geotechnical context,

-AVOI, ENVI and RISK also deals with modeling, but respectively focus on the impact on the surrounding constructions and utility networks, the natural environment and the assessment of potential technical risks on the project.

-CALC and MECO are preconization phases that aims at modeling the interface between the infrastructure and its environment and proposing sustainable sizing and design (CALC) and construction method (MECO) to build the project.

The process starts with the collection of observations. The creation of models aims at characterizing the construction site and enable to propose solutions to integrate the infrastructure. Then feedback that would be obtained during the construction and maintenance (yet out of scope of that project) could enable to update the models and ensure the expected fidelity between the model(s) and the real world, as targeted by BIM.

\subsubsection{Information Delivery Manuals (IDM)}

In order to describe the steps, actors and formats used for geotechnical «knowledge» construction, Information Delivery Manual (IDM) were developed. Each IDM consists in a process map and a glossary.

The process map provides a graphical representation of the sequence of activities in the topic and the involved data. As recommended by ISO29481, it is based on the BPMN language. An example of process map is shown below:

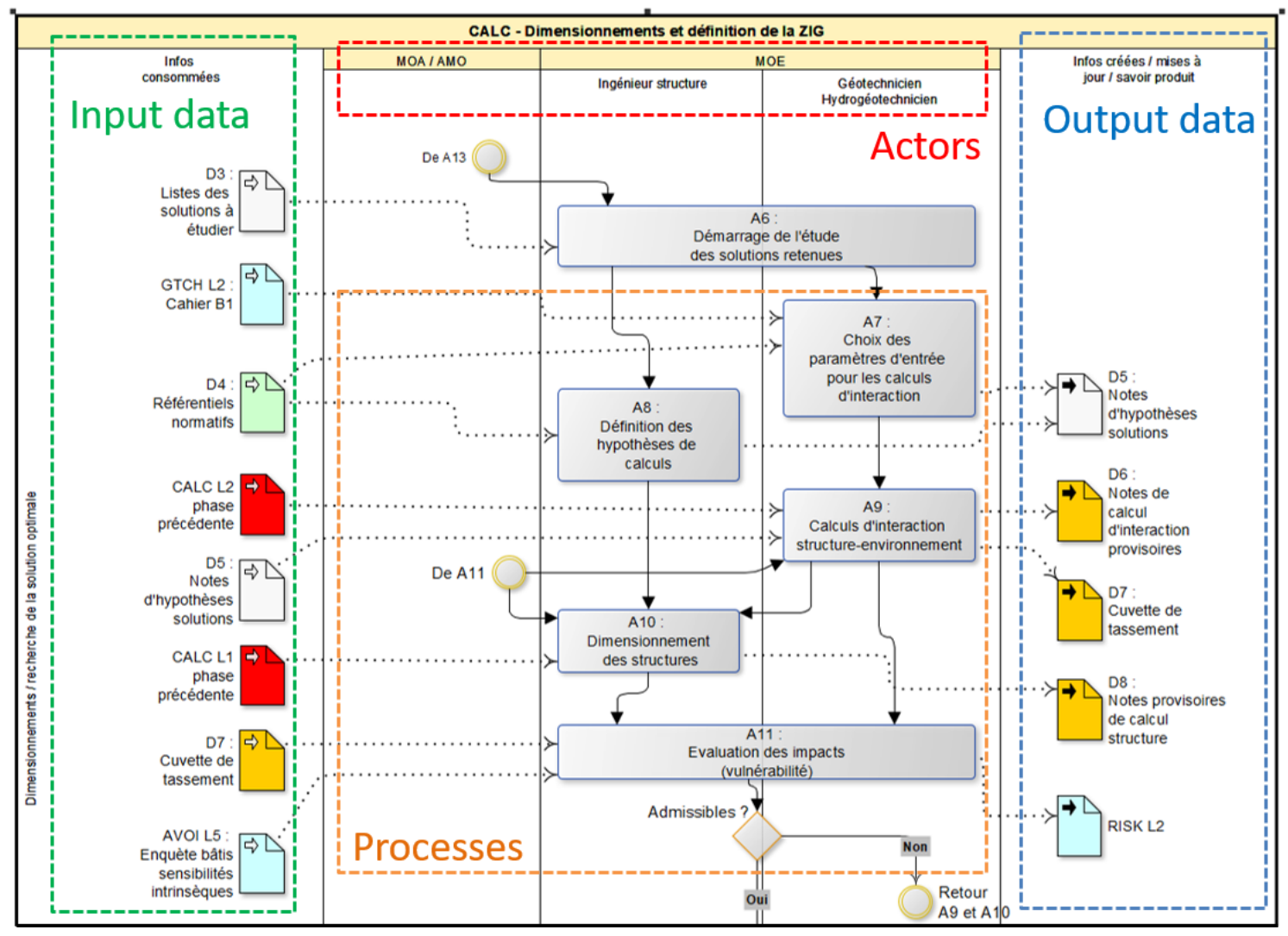

Figure 2: Extract from the CALC IDM (Infrastructure sizing from assessment of interaction with soil)

The progression of the project and thus the sequence of processes can be read from top to bottom. The realization of a process in terms of consumption / modification / production of knowledge is read from left to right. 
The glossary acts as a legend for the process map and enable to provide more detailed description of both data and actions.

IDMs enable to define which data are handled, who instantiate it, who should be able to update it or just access it, thus the basic information to imagine a collaborative platform to share the data, as depicted by BIM Level 3. Such information is also crucial to define the right semantics and features to integrate in the conceptual model and the definition of model views (MVD) that would enable to fulfill the project flow.

\subsection{Geotechnical data interoperability issues and challenges}

The several IDM that were developed expose how the "geotechnical knowledge" is supposed to be built, but even if this vision is shared by the community and introduced in a standard, sometimes practices can differ and affect data exchanges.

\subsubsection{Actors and task repartition}

In some circumstances, two or more roles or jobs that have been identified in the IDM can be assumed by one unique person. Motivations for such approach are often economical and aims at reducing the data exchange (thus delays) by merging the actors. In that case, some data exchanges would not happen. Yet in order to keep the lineage, thus facilitate correction, it is strongly recommended to keep the proposed decomposition of result furniture, especially if there are specifically reused for another process.

\subsubsection{Tools interoperability issues}

Inherent to the exchanges between people having different roles is the use of different tools adapted to their job. This technical issue is increased by the presence of several software introducing their own data format. Another issue is that tenders do not always specify or enforce the format that shall be used to provide the data. For investigation contract for example, this may lead to the furniture of borehole data in very different formats: picture format (pdf), text (txt, Word, ...), spreadsheet (Excel, ...) or database (Access, AGS, ...). This can result in the best case into data conversion thus "only" time waste, yet in the worst case (e.g. image format) into the need to entry the data again, with associated mistake risk.

\subsubsection{Semantic issues}

Another issue is the use of different semantics to characterize the information. This is particularly usual as geotechnics involve several jobs (geologist, hydrogeologist, geotechnical engineer, driller, ...). Then two actors may rely on different types of classification, introducing confusion in the lecture and comprehension of the data. In the best case, this issue may be solved with value conversion. Yet if not mentioned this can lead to mistake or errors (e.g. unit format). To avoid that issue, reference to a common data dictionary or vocabulary shall be mandatory.

\subsubsection{D modeling}

In opposition to BIM for building design, geotechnical modeling is not (for now) always associated to 3D modeling. Particularly for linear infrastructures, 2D cross sections remain a very common way (if not the most common) to map the subsurface. Until 3D geomodeling become mandatory, a solution to deal with integration of geomodels into BIM models shall consider this state and not been limited to 3D modeling.

\section{GEOTECHNICAL DATA AND EXISTING STANDARDS OVERVIEW}

The construction of the IDMs enabled to identify the concepts and data that compose and represent the "geotechnical knowledge". This part proposes a summary and classification of the identified concepts, as well as an overview of existing standards and initiatives that address the geotechnical topic. 


\subsection{Main concepts in geotechnics}

\subsubsection{Observations and measurements}

Geological, geotechnical or hydrogeological models are built from data provided during reconnaissance surveys. These data describe different types of objects with specific properties. The main data come from observations or measurements of the soil or nearby structures. The MINnD UC8-GT group adopted the following typology:

Observations:

-Surface observations: these observations concern all the data provided during a field trip by a geologist or a geotechnical engineer. In most cases, these are diagrams, notes. These documents are accompanied by georeferenced photos of the different areas. These observations enable to provide analysis data that can take the form of an analysis of lithology and structural geology.

-Deep field observations: These observations are provided through drilling. The first observation comes from the indications of the driller during the progress of drilling. When core drilling is done, then it is possible to extract the soil to analyze it.

Measurements:

-Topography: This measure is a basic measure that serves as a shared foundation for all geotechnical data. 3D topographic data is becoming simpler to acquire thanks to easily accessible technologies such as lidar or photogrammetry.

-In situ geotechnical tests: This term includes all the tests that can be performed during a geotechnical survey. Pressuremeter or penetrometer tests are the most famous example of in situ geotechnical tests. During in situ test, the measurement of a water level is an important measure to know the state of the aquifer.

For these geotechnical measurements, it must be ensured that the data has been validated by a geotechnical engineer based on the raw data, that is to say, the data directly obtained from the tests (pressure, deformation, ...).

-Geophysical measurements: these measurements are different from in situ tests because geophysical measurements are non-destructive tests. The most widely used geophysical measurements are seismic, electrical or electromagnetic ones.

-Geotechnical laboratory tests. These tests concern all the geotechnical tests which are carried out not in the field, but in a laboratory. The best known are triaxial tests, oedometric tests or granulometry.

-Real time monitoring. Measurements made by sensors, for example piezometers or monitoring of nearby structures.

\subsubsection{Models}

In addition to data observed or measured on site, whatever if they are interpreted or raw data, the other type of data exchange is all analysis and design performed by specialist. This kind of data is named "model". The principal model, the geotechnical model, is a summary of information from three main fields of expertise: geology that enables to define the general structure of the subsurface including fault presence, hydrogeology that informs the presence of water and geotechnics that determine its geomechanical properties. These model aims at synthetizing and improving data collected in useful information for construction.

Their second objective is to define the degree of uncertainty of model in order to assess the risk of construction. In addition, model could propose additional investigation to improve the quality of data measured, in order to limit the degree of uncertainty and so the risk.

According to that, each data introduced in general model (for structure design) must propose an associated degree of uncertainty and the way to limit it. This approach follows the classical workflow of geotechnical design (AFTES guidelines). Design done in prefeasibility study is a global interpretation of environment. Whereas detailed design study seeks to define more accurately the soil behavior.

Coupled to this model, impact of construction on environment (built and unbuilt) is also assessed. It is generally done (in tunnel design) by defining the expected surface settlement due to construction. This mapping is then cross-checked with existing building tolerance coming from in situ measurement assessment (AVOI). At last environmental aspect (pollutant material, excavated soil management) is studied. 


\subsection{Standards for geoscience data}

An important standardization effort exists for geoscience related data. As an output several, open and non-open standards address the concepts/information needs presented in this paper. Several standardization 'silos' are important here.

ISO 191xx series:

- Provides the international framework under which most of the open standards are built (especially for the OGC and INSPIRE ones).

- ISO 19156 Observations \& Measurements: is the key central standard framing the Observations and Sampling topics. Many domain standards are indeed specialization of it.

Open Geospatial Consortium (OGC) joint standards with the International Union of Geological Sciences Commission for Geoscience Information (CGI-IUGS)

- GeoSciML (Geoscience Markup Language) covers the domain of geology (earth materials, geological units and stratigraphy, geological time, geological structures, geomorphology, geo-chemistry) and sampling features common to the practice of geoscience, such as boreholes and geological specimens (Boisvert \& al., 2017).

- GroundWater Markup Language 2 (GroundWaterML 2 or GWML2) is a data exchange standard for the groundwater domain. As part of the WaterML 2.0 standard and linked to GeoSciML, it introduces concepts such as hydrogeological units, fluid bodies, voids, flow, well, borehole construction, geological logs, management area (Brodaric \& al., 2017).

INSPIRE Directive themes

- The geology theme formalizes the geology, groundwater and geophysics domains. It does have an important overlap with GeoSciML and GWML2 semantic content but also provide new structure for 'orphan' domains (ex: geophysics). Most of GeoSciML European people where involved in specifying that theme.

- Other INSPIRE themes can enrich the data panel such as 'Environmental monitoring facilities' which describes monitoring facility/networks, observation campaign and observation acquired or 'Soil'.

Industry

- The Energistics consortium propose standards RESQML and WITSML that respectively enable reservoir characterization and wits description (King, 2012). These formats are designed for the Oil \& Gaz topic, yet some concepts might be reused for geotechnics.

- The AGS Data Format for geotechnics is an English initiative that provide a format to transfer ground investigation, laboratory testing and monitoring data. A project called DIGGS (Caronna, 2006) aimed providing a XML compliant format for AGS, yet this has not been officially adopted by AGS.

National standards

- Some countries also define their national data standard(s). They do not always re-use (build-on) the international initiatives previously mentioned. Even though some are willing to align with them for the same reasons as the one mentioned at the beginning of that chapter. Borehole ML, German standards on Borehole is worth mentioning here.

It is also important to understand standardization dynamics and the communities pushing them. Within the research community:

- EPOS EU Research Infrastructure made an important push in enhancing Borehole data discoverability,

- ESIP/RDA Earth, Space, and Environmental Sciences Interest Group aims to act as an 'umbrella' group trying to bring together parties from the big international research infrastructures.

Two recent activities initiated under the OGC also make a change in the standards picture in the domain. As such, the OGC Geoscience Domain Working Group gathers (if not all) the mentioned standardization 'silos' to discuss how to create bridges between the various standardization efforts. On a specific topic, the recently started OGC Borehole Interoperability Experiment (http://www.opengeospatial.org/projects/initiatives/boreholeie) builds on EPOS EU research infrastructure Borehole model and aims to test/refine it against a handful of use cases stemming from the various communities (research, Oil \& Gas, , ... and geotechnics). 


\section{PROPOSITION FOR GEOTECHNICAL DATA STANDARDIZATION AND MANAGEMENT}

\subsection{Conceptual model}

Standards update and their implementation is a somewhat iterative approach. Thus, the MINnD UC8-GT group proposed a best approach for each of the identified concept as of today's dynamics. Needs identified in parts 2.2 and 3.1 have been confronted to the standards described in the previous part. Most (if not all) the needs identified are covered in one of the standards. The best approach proposed is the following.

Concepts and semantic for structural geology:

- Geologic units and geologic structures can be described using GeoSciML keeping in mind the flexibility offered by the concept of MappedFeature which allows to differentiate the real world object and its various representation one can encounter in various maps (different scale, levels of details, ,...).

Concepts and semantic for hydrogeology:

- GWML2 stems from the hydro Domain Working Group also with the goal to ensure the continuity in the description of surface/ground water flows. In combination with OGC HY_Feature conceptual model, it ensures a global understanding of the water cycle. It is recommended to describe underground hydrologic features and their associated flow models with those standards.

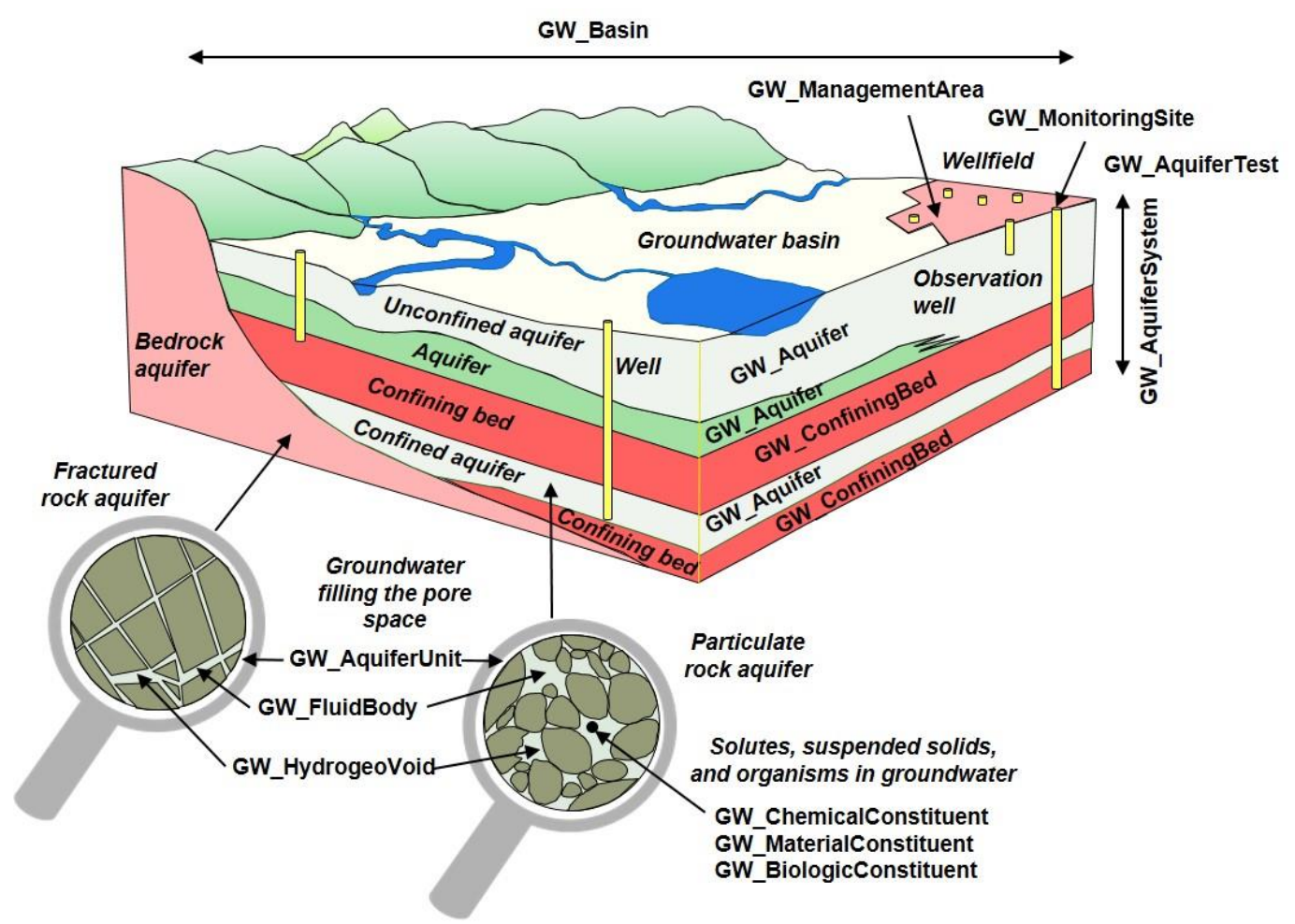

Figure 3: Some concepts from the OGC GroundWaterML2 model (Brodaric, 2017)

Concepts and semantic geotechnical modeling:

- Geotechnical modeling can be seen as a combination of structural geology and hydrogeology modeling with the fusion/refinement of proposed division of the subsurface in geologic units based on several properties. Thus, geotechnical modeling data exchange could be achieved using the same concepts as for the two previous domains. Yet additional geotechnics specific vocabulary might be necessary to add.

Concepts and semantic for impact on surrounding constructions:

- In the interoperability standards landscape, surrounding constructions can be described using CityGML and/or INSPIRE Building Theme. UtilityNetworkADE extension for CityGML and/or INSPIRE UtilityNetworks Theme can also be used. 
Concepts and semantic for impact on the natural environment:

- INSPIRE themes 'Natural Risk Zones' and 'Area management/restriction/regulation zones and reporting units' can be a good starting point to describe the impact of a given project on its direct environment. Concepts of HazardArea, RiskZone, ExposedElements are good candidate for such a goal.

Observations and measurements:

- In order to describe observations collected on the field, Observations \& Measurements contains all the necessary elements. The more "domain specialized" standards often propose pattern to use O\&M for specific observations (ex: GeoSciML with an outcrop dedicated pattern, GWML2 with a pump test one,...). Logs are described in several standards. However, GWML2 takes the point of view that a log is an Observation per se, thus provide a specific O\&M based pattern to do so. This is the recommended approach.

- Laboratory analysis can also be described using O\&M. Depending on the types of the context, starting from GeoSciML Laboratory and Analysis package (based on O\&M) might be recommended. It is a model for laboratory analytical metadata, geological sampling and specimens, and isotopic age observation results. The AGS data format is also studied as a main source of inspiration for the description of the geotechnical tests and analysis.

Survey and models:

- The concept of "Campaign" appears in the INSPIRE model, in the geology them / geophysics package. In that context, it is defined as an activity that consists in producing (geophysical) data, processing results or models. It provided the necessary hook to O\&M.

- As for Geological Models, a first attempt of UML modelling also appears in INSPIRE Geology / geophysics package (Geophysical model focused). It proposes to describe them using O\&M. Based on this, EPOS EU research infrastructure proposed a short summary UML description of a geological model that aims, in turn, to point back to a more thorough description using O\&M. This is the approach currently pushed by the community.

\subsection{Data management}

Beside conceptual models, OGC introduces standard interfaces that enable to retrieve data and expose them on the web. Most famous standards from OGC is the Web Mapping Service (WMS) that enable to provide a map (image) representation from several GIS vector or raster data formats. Yet other OGC standards enable to expose data: Web Feature Service (WFS) to provide discrete geospatial objects, Web Coverage Service (WCS) to provide coverage, Sensor Observation Service (SOS) and Sensor Things API to provide observations and measurements.

The standardization approach concern two steps: first is the protocol to use to ask the server for specific data including filtering capacities. Second is the format and model that the result obtained conform to. In other words, such web services enable the "consumer" to build a query with a standardized syntax to get standardized data on demand without having to figure the data storage systems and format used by the provider. Use of such standards is interesting for the development of sustainable Spatial Data Infrastructures (SDI), which consists in platforms that offer users to access and share data in a collaborative way. In addition, Pub/Sub type solutions (OGC, 2013) would offer capacities to notify users of the update of some data. IDM described in the first part of that paper indicates which notification shall be transmitted to continue the geotechnical processes. Applicated to building information modeling data, such system could propose first bricks to build the collaborative data platform depicted by BIM Level 3. Use of WFS to provide IFC have even been suggested by (Schumann, 2017).

\section{CONCLUSION AND PERSPECTIVES}

While BIM model aims at providing the most accurate description of a projected construction, environmental modeling follows the scientific method to provide an interpretation of the subsurface organization and behavior. Then in the construction domain, the geotechnical activity consists in the realization of several models that once linked lead to the proposition of methods, infrastructure sizing that shall ensure the builders to have the project realized with acceptable risk conditions. 
The MINnD UC8-GT team focused on the identification of the geotechnical data that are formally exchanged in a project. The results are represented by Information Delivery Manuals (IDM) that describe the geotechnical knowledge construction. It enabled to identify the important concepts to include in a data model proposition. Furthermore, it highlights that the interaction between the geotechnical engineering team and the civil engineering team does not (only) rely on the provision of a "map" of the subsurface. This means that current propositions of IFC extensions for geology or geotechnics that deal with the provision of representations of geological model (may it be 1D (borehole log), 2D (cross section) or 3D), only address a part of the required and formally exchanged geotechnical information.

Yet, several groups or organizations, such as INSPIRE and OGC already propose data models for geoscience data standardization. Those models are developed, supported and implemented by the geoscience community. As most concepts (if not all) needed for geotechnical data exchanges are introduced in those models, proposition from MINnD UC8-GT is to rely on them. A best approach mapping is then proposed to indicate which model or standard to use for each identified data to exchange. Implementing existing standards, especially open ones, is recommended for many reasons. With no specific order, it triggers better semantic and technical interoperability between parties involved in a project. Then tools (open source, vendors) can already be available. Those tools can range from data provision (e.g. data server), to data consumption (e.g. desktop client). In addition, in some geographical contexts, it allows to respect legal obligations (ex: INSPIRE directive in Europe - Directive 2007/2/EC). Those points have a direct impact on the costs efficiency of an approach based on those. Indeed, there is no (or less) need to adapt tools to each new customer and data context. Thus, a better Return On Investment at company/project level.

Finally, connecting building models and geomodels is a key use case for the BIM / GIS interoperability, bSI and OGC, as respective representatives of BIM and GIS, bSI and OGC data shall work together to build a common conceptual model for geotechnical concepts that would ensure the semantic interoperability. Such approach has already been successfully achieved with the alignment concept model that is identical for both bSI IFC Alignment and OGC LandInfra models (Scarponcini, 2016).

\section{REFERENCES}

An, Y. 2017 - Geological Data Extension for Subway Tunnel BIM models using a Linked Data Approach - Master Thesis. Eindhoven Technical University. March 2017

BNTRA, 2014 - Liste des normes françaises du domaine Géotechnique - Version du 31 mars 2014. Bureau de Normalisation des Transports, des Routes et de leurs Aménagements.

Boisvert, E. \& al., 2017 - Geoscience Markup Language 4.1 (GeoSciML) - Open Geospatial Consortium Standard 16-008, v4.1, 247 p.

Braeckel, A. \& al. 2013 - OGC® Publish/Subscribe Interface Standard 1.0 - Core - Open

Geospatial Consortium Standard 13-131r1, v1.o, 112p.

Brodaric, B. \& al., 2017 - OGC WaterML 2: Part 4 - GroundWaterML 2 (GWML2) - Open Geospatial Consortium Standard 16-032r2, v2.2, 160p.

Caronna, S. 2006 - Implementing XML for geotechnical databases - Geo-Engineering Data:

Representation and Standardisation, 10th IAEG Congress September 9th 2006 Nottingham, UK.

China Railway BIM Alliance. 2015 - CRBIM 1002-2015: Railway BIM Data Standard (Version 1.0) - China, December 29, 2015.

Eastman, C. Teicholz, P., Sacks, R., \& Liston, K. 2011 - BIM handbook: a guide to building information modeling for owners, managers, designers, engineers, and contractors - Wiley.

King, M. \& al. 2012 - Reservoir Modeling: From RESCUE to RESQML - SPE Reservoir Evaluation \& Engineering. Vol 15. Issue 2. 12p.

NF P 94500 - Geotechnical engineering missions - Classification and specifications.

NF EN 1997-1/1997-2 - Eurocode 7 : Calcul géotechnique.

Scarponcini, P. \& al. 2016 - OGC® Land and Infrastructure Conceptual Model Standard (LandInfra) - OGC ${ }^{\circledR}$ Implementation Standard 15-111r1, v1.0, 315p.

Schumann, G. \& al, 2017 - Future City Pilot 1 - Recommendations on Serving IFC via WFS OGC Public Engineering Report. 15p. 